SPIE 4701-60

\title{
Structural acoustic response of a shape memory alloy hybrid composite panel (lessons learned)
}

\author{
Travis L. Turner* \\ NASA Langley Research Center
}

\begin{abstract}
This study presents results from an effort to fabricate a shape memory alloy hybrid composite (SMAHC) panel specimen and test the structure for dynamic response and noise transmission characteristics under the action of thermal and random acoustic loads. A method for fabricating a SMAHC laminate with bi-directional SMA reinforcement is described. Glass-epoxy unidirectional prepreg tape and Nitinol ribbon comprise the material system. Thermal activation of the Nitinol actuators was achieved through resistive heating. The experimental hardware required for mechanical support of the panel/actuators and for establishing convenient electrical connectivity to the actuators is presented. Other experimental apparatus necessary for controlling the panel temperature and acquiring structural acoustic data are also described. Deficiency in the thermal control system was discovered in the process of performing the elevated temperature tests. Discussion of the experimental results focuses on determining the causes for the deficiency and establishing means for rectifying the problem.
\end{abstract}

Keywords: Shape memory alloys, Nitinol, embedded actuators, hybrid composites, random response, acoustic response

\section{INTRODUCTION}

Shape memory alloys (SMAs) have been the subject of active research for over three decades due to their many unique attributes and the resulting potential for a variety of applications. Early work focused on alloy characterization and discovery of some of the fundamental micromechanical phenomena responsible for the unique properties. A variety of applications ranging from self-erecting structures and energy-conversion devices to thermally actuated fasteners and biomedical devices were also identified in this early effort. Metallurgical work in recent years has seen significant growth, partly due to a substantial increase in applications research that has been stimulated by interest from the biomedical and smart materials communities. Recent smart materials and structures work has shown that SMAs have significant potential for vibration, structural acoustic, and structural shape control applications. Birman ${ }^{1}$ published a comprehensive review of the work performed in the areas of SMA constitutive modeling and applications. Several compilations of papers have also been published on the topic, most recently by Otsuka and Wayman ${ }^{2}$, which give a good overview of the alloy characteristics and an introduction to applications.

The shape memory effect has been employed for various applications since its discovery, some of which were mentioned previously. A new class of applications was developed when Rogers and Robertshaw ${ }^{3}$ introduced the idea of embedding SMA actuators in a composite laminate for structural control. A structure of this type has been termed a shape memory alloy hybrid composite (SMAHC). Paine and Rogers published a review of SMAHCs and their applications ${ }^{4}$. Two methods have been proposed for integrating SMA actuators into a composite: bonding the actuators within the composite matrix as a constituent and embedding the actuators within sleeves through the laminate. The work presented in this study focuses on the former method, where prestrained actuators are bonded within the composite matrix and the boundaries of the structure serve also as mechanical restraints for the actuators. Recent work has considered SMAHC structures for static and dynamic structural response control. Frequency response limitations of the SMA (dictated by thermal energy management) have often been cited as an obstacle for dynamic control. However, there are many applications in which a naturally occurring elevated thermal environment can be used to activate the SMA autonomously. The activated SMA actuators act against the mechanical boundaries to adaptively stiffen the structure without control electronics or auxiliary power.

\footnotetext{
*t.l.turner@larc.nasa.gov; phone 1757 864-3598; fax 1757 864-8823; http://stab.larc.nasa.gov; Structural Acoustics Branch, Mail Stop 463, Hampton, VA 23681-2199
}

SPIE's $9^{\text {th }}$ Annual International Symposium on Smart Structures and Materials; Smart Structures and Integrated Systems, L. Porter Davis (Editor), SPIE Vol. 4701, Paper No. 4701-60, San Diego, CA, 17-21 March 2002. 
Previous work has been done to investigate the thermal, static stability, and dynamic characteristics of SMAHC panels with SMA actuators embedded in sleeves ${ }^{5-7}$. The elastic stability of sandwich panels with functionally graded SMA inclusion has also been considered ${ }^{8}$. Other studies have considered the active vibration and structural acoustic control of simply supported panels by embedded SMA actuators ${ }^{9-11}$. Recent work at NASA LaRC has demonstrated numerical modeling of SMAHC structures ${ }^{12,13}$, fabrication and characterization of SMAHC beam specimens ${ }^{14}$, measured static and dynamic responses of SMAHC beam specimens, and correlation of the measured responses with numerical models ${ }^{15,16}$. The focus of the present study is to extend the fabrication effort to panel-type specimens with bi-directional SMA reinforcement, test the structure for dynamic and noise transmission characteristics, and extend the numerical modeling/correlation to this more practical configuration.

\section{BACKGROUND}

In the typical application under consideration, such as adaptive stiffening of aerospace structures, the SMA elements would be activated through an inherently elevated temperature of the service environment. This effect can be simulated in experiments by various means, of which the most practical is resistive heating. A glass-epoxy matrix material system was selected to avoid any potential electrical conduction problems. This material system also affords the advantage of visual flaw detection due to its translucency. A Nitinol alloy was selected because of favorable electrical resistance, availability, and shape memory capabilities.

Glass-epoxy unidirectional prepreg tape was obtained from Fiberite, Inc. The material is Hye 8 End/934, an E-glass/934 epoxy resin material system. The resin material is formulated for autoclave processing and the following cure procedure is recommended; heat at $1.1-2.8^{\circ} \mathrm{C} /$ minute $\left(2-5^{\circ} \mathrm{F} /\right.$ minute) to $121.1^{\circ} \mathrm{C}\left(250^{\circ} \mathrm{F}\right)$ and hold for 15 minutes, apply $689.5 \mathrm{kPa}$ (100 psig) pressure and continue to hold at $121.1^{\circ} \mathrm{C}\left(250^{\circ} \mathrm{F}\right)$ for an additional 45 minutes, heat at $1.1-2.8^{\circ} \mathrm{C} / \mathrm{minute}(2-$ $5^{\circ} \mathrm{F} /$ minute) to $176.7^{\circ} \mathrm{C}\left(350^{\circ} \mathrm{F}\right)$ and hold for 120 minutes, and cool at $2.8^{\circ} \mathrm{C} /$ minute $\left(5^{\circ} \mathrm{F} /\right.$ minute) (maximum) to ambient.

A Nitinol alloy in a ribbon form was selected, in lieu of a wire form, as the actuator material in this study to simplify the fabrication procedure, allow for more flexibility in fabrication, and desensitize the actuators to interface voids and stress concentrations. This approach was adopted because recent SMAHC fabrication efforts involving wire-type actuators have suffered from various disadvantages. These disadvantages include complicated fabrication procedures because of the relatively large number of actuators usually needed, sensitivity to actuator/matrix interface flaws because voids can be of significant relative size, and relatively high rate of actuator breakage during cure because of sensitivity to stress concentrations at the mechanical restraints. Finally, it is difficult to achieve a desirable overall volume fraction of SMA in wire form when trying to optimize the integration of the actuators by placing them in only selected layers. Conversely, ribbon-type SMA elements can be placed in strips cut out of particular matrix laminae to result in a rather simple lay-up operation, while keeping the volume fraction high in the desired locations.

A Nitinol alloy was specified with an appropriate composition to give a martensite finish temperature above the expected ambient temperature while maintaining an austenite finish temperature well below the glass-transition temperature of the Fiberite 934 epoxy matrix $\left(193.3^{\circ} \mathrm{C}, 380^{\circ} \mathrm{F}\right)$. Shape Memory Applications, Inc. provided the Nitinol ribbon material with nominal transformation temperatures, in a fully annealed state, of $\mathrm{A}_{\mathrm{s}}=67^{\circ} \mathrm{C}, \mathrm{A}_{\mathrm{f}}=85^{\circ} \mathrm{C}, \mathrm{M}_{\mathrm{s}}=46^{\circ} \mathrm{C}$, and $\mathrm{M}_{\mathrm{f}}=32^{\circ} \mathrm{C}$. Differential scanning calorimetry (DSC) and direct current plasma (DCP) emission tests were performed on samples to determine the condition of the material in the as-received state. The transformation temperatures for the Nitinol in the as-received condition and in a free configuration were determined to be approximately $\mathrm{A}_{\mathrm{s}}=45^{\circ} \mathrm{C}\left(113^{\circ} \mathrm{F}\right), \mathrm{A}_{\mathrm{f}}=60^{\circ} \mathrm{C}$ $\left(140^{\circ} \mathrm{F}\right), \mathrm{M}_{\mathrm{s}}=17^{\circ} \mathrm{C}\left(62.6^{\circ} \mathrm{F}\right)$, and $\mathrm{M}_{\mathrm{f}}=0^{\circ} \mathrm{C}\left(32^{\circ} \mathrm{F}\right)$. The average results of the DCP analyses are $55.4 \mathrm{Ni}-44.3 \mathrm{Ti}-0.033 \mathrm{C}-$ $0.1965 \mathrm{O}-0.0011 \mathrm{H}-0.0075 \mathrm{~N}-0.0075 \mathrm{Fe}$; wt $\%$. Further detail of these analyses can be found elsewhere ${ }^{14}$.

A panel-type specimen was designed using the previously mentioned numerical model. A schematic of the specimen is shown in Figure 1. Parameters influencing the specimen design include the use of ribbon-type actuators, fabricationtooling geometry, and dynamic range of anticipated experimental configurations. The specimen design is by no means optimized, but the predicted performance is in a range that is suitable for the expected loading conditions and to demonstrate significant improvement from the SMA reinforcement.

SPIE's $9^{\text {th }}$ Annual International Symposium on Smart Structures and Materials; Smart Structures and Integrated Systems, L. Porter Davis (Editor), SPIE Vol. 4701, Paper No. 4701-60, San Diego, CA, 17-21 March 2002. 
Note that this specimen design calls for a lamination of $(45 / 0 /-45 / 90 / 0 / 90 /-45 / 0 / 45)$ with a SMA actuator cross section of $0.0127 \times 1.27 \mathrm{e}-4 \mathrm{~m}(0.5 \times 0.005$ inches $)$ to be embedded within each of the outer two $0^{\circ}$ and the $90^{\circ}$ glass-epoxy layers, i.e., replacing a portion of each layer. Material availability and processing limitations dictated a nominal Nitinol ribbon cross section of $0.0023 \times 1.5 \mathrm{e}-4 \mathrm{~m}(0.09 \times 0.006$ inches $)$. This thickness was considered acceptably close to the estimated glass-epoxy unidirectional tape thickness $(1.27 \mathrm{e}-4 \mathrm{~m}, 0.005$ inches) and it was planned that five widths of the ribbon would be placed side-by-side to develop a width near that in the specimen design.

\section{SPECIMEN FABRICATION AND CHARACTERIZATION}

The SMAHC specimen fabrication procedure used in this study consists of the following steps; prestrain (elongate) the SMA actuators, lay-up the composite laminate, cure the laminate while restraining the actuators, and machine the specimen for installation in test fixtures. This procedure is consistent with that previously presented for fabrication of beam specimens, but some detail is given here for clarity and completeness because the panel specimen is more complex. Additional detail on the actuator processing and specimen fabrication process can be found in a related publication $^{14}$.

SMA actuators are frequently trained prior to placing them in service. The training process typically involves imparting the desired elongation to the actuators and subjecting them to prescribed thermomechanical cycling that renders the cycle hysteresis stable. An alternate approach of quantifying the cycle-dependent thermomechanical properties of the actuators was adopted for the present study because training processes are very cost/time intensive and a large number of actuators were needed for fabrication of the specimen shown in Figure 1.

The prestrain operation employed in this work consisted of removal of the packaging strain and imposition of a prescribed level of axial elongation. Packaging strain is undesirable deformation induced in the SMA material subsequent to heat treatment, such as spooling the material for storage and/or shipping. The packaging strain was removed in the present process by subjecting actuator lengths to resistive heating in a device designed to impose minimal axial constraint while applying lateral constraint to force the actuator to return to its flat, straight memorized configuration.

The prestraining operation needs to be very controllable, precise, and repeatable because the actuators are very easily deformed during handling in the martensitic state and the actuator performance is a very strong function of prestrain level. An apparatus was developed to align and maintain proper geometry on three ribbon lengths concurrently, while installing them in a tensile test machine. In the particular case of the specimen in Figure 1, a total of 220 actuators with a gage length of $0.635 \mathrm{~m}$ ( 25 inches) were installed in the test machine, three at a time, and elongated $4 \%$ to a gage length of $0.66 \mathrm{~m}$ ( 26 inches). This gage length was used in order to ensure uniform prestrain over the $0.6604 \mathrm{~m}$ ( 26 inch) span between mechanical restraints on the composite lay-up tooling plate, which will be discussed subsequently.

A mechanical drawing of the lay-up and cure tooling plate is shown in Figure 2. This apparatus was designed to provide a flat surface ( \pm 0.005 inches) and mechanical grips to restrain the SMA during an autoclave cure procedure. Recall that the panel specimen design calls for a lamination of $(45 / 0 /-45 / 90 / 0 / 90 /-45 / 0 / 45)$ with the Nitinol in the outer two $0^{\circ}$ and in the $90^{\circ}$ layers. This lamination was accomplished by cutting widths of those layers to size during assembly and filling the void with five ribbon widths laid side-by-side. The laminate after complete assembly is shown in Figure 3, where it can be seen that the Nitinol ribbon ends have been secured within the knurled mechanical restraints. Note that Kapton release film, fiberglass breather cloth, and teflon-coated fiberglass bleeder cloth are layered between the tooling plate surface and the first glass-epoxy layer, in that order. The mechanical restraints consisted of three parts; the tooling plate surface, a thin spacer with knurling on both sides, and the top clamping bar. This arrangement was employed to minimize bending of the actuators between the laminate boundary and the restraint and to maximize grip for each layer of SMA by gripping the separate layers independently. The mechanical restraint screws received a torque of $11.30 \mathrm{~N} \cdot \mathrm{m}$ (100 in $\cdot 1 \mathrm{bf}$ ). The surfaces of the protruding Nitinol ribbon ends and all gripping surfaces of the mechanical restraints were coated with a release agent to promote removal of resin overflow. Subsequent to assembly, the laminate was topped with bleeder cloth, Kapton film, a caul plate, bleeder cloth, and breather cloth, in that order. The entire assembly was vacuum bagged and drawn to an internal pressure of $0.0475 \mathrm{~atm}$.

SPIE's $9^{\text {th }}$ Annual International Symposium on Smart Structures and Materials; Smart Structures and Integrated Systems, L. Porter Davis (Editor), SPIE Vol. 4701, Paper No. 4701-60, San Diego, CA, 17-21 March 2002. 
The assembly was subjected to the autoclave cure cycle recommended by the vendor and the resulting consolidated part is shown in Figure 4, where it can be seen that fastener holes have been machined in the panel as per the specifications in Figure 1 . The dimensions of the panel are $0.559 \times 0.508 \times 0.0011 \mathrm{~m}(22 \times 20 \times 0.045$ inches $)$. The overall volume fraction of the SMA within the glass-epoxy dimensions is approximately $26 \%$.

Thermomechanical tests were performed on the constituents of this material system in order to gain a better understanding of the mechanics of the hybrid composite and to facilitate comparison with numerical models. Tests were performed on glass-epoxy-only specimens to determine the properties of the composite matrix in principal material coordinates (PMC). Tests were performed on uniaxial $(0)_{20}$ specimens according to ASTM 3039-95a for estimates of the Young's moduli $\left(E_{1}\right.$ and $\left.E_{2}\right)$ and Poisson's ratios $\left(v_{12}\right.$ and $\left.v_{21}\right)$. Similar tests were performed on angle-ply $( \pm 45)_{4}$

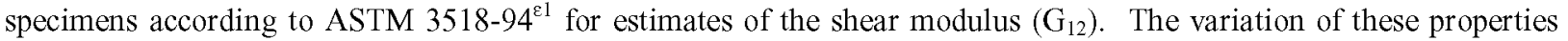
with temperature is shown in Figure 5. As expected, the fiber direction modulus is fairly constant, but the transverse and shear moduli show some nonlinearity. Specimens for the measurement of the longitudinal and transverse CTE, also in PMC, were machined from the same uniaxial laminate $(0)_{20}$. Results from these tests are shown in Figure 6, which shows substantial nonlinearity with temperature. These nonlinearities may be partly due to drying of the resin material.

The Nitinol alloy was tested to quantify the recovery stress versus temperature and thermal cycle, in lieu of training, and the modulus versus temperature. The recovery stress was measured by installing samples of the Nitinol ribbon with 4\% prestrain, remaining from SMAHC specimen fabrication, in a servohydraulic test machine. Samples were subjected to thermal cycles by resistive heating while measuring the force generated as a function of temperature. Representative results showing the average recovery stress versus temperature for thermal cycles 2, 3, 4 and 50 are presented in Figure 7. Significant changes were observed in the character of stress-temperature behavior out to 50 cycles, where the behavior appeared to stabilize. The Young's modulus of the prestrained ribbon was estimated from tensile test data performed on the test machine using a box furnace. Tests were conducted on 3 ribbon samples at each of 7 temperatures; $21.1^{\circ} \mathrm{C}\left(70^{\circ} \mathrm{F}\right), 37.8^{\circ} \mathrm{C}\left(100^{\circ} \mathrm{F}\right), 65.6^{\circ} \mathrm{C}\left(150^{\circ} \mathrm{F}\right), 79.4^{\circ} \mathrm{C}\left(175^{\circ} \mathrm{F}\right), 93.3^{\circ} \mathrm{C}\left(200^{\circ} \mathrm{F}\right), 121.1^{\circ} \mathrm{C}\left(250^{\circ} \mathrm{F}\right)$, and $148.9^{\circ} \mathrm{C}\left(300^{\circ} \mathrm{F}\right)$. Modulus estimates from the three samples were averaged and the resulting modulus versus temperature behavior is shown in Figure 8. Additional detail on the thermomechanical testing of the constituent materials can be found elsewhere ${ }^{14,16}$. Tabulated data from the thermomechanical tests also appear in those publications.

It is widely known ${ }^{17,18}$ that the transformation characteristics and thermomechanical properties of shape memory alloys are strong functions of thermomechanical processing. Thus, accurate thermomechanical modeling of such a material system requires careful attention to the condition of the SMA actuators when they are put into service, and testing of the material properties under corresponding conditions. An example of this effect was reported recently ${ }^{14}$, where a dramatic difference was shown between the tensile behaviors of a Nitinol ribbon actuator with $4 \%$ prestrain and an equivalent actuator after having been exposed to one thermal cycle from ambient temperature to $148.9^{\circ} \mathrm{C}\left(300^{\circ} \mathrm{F}\right)$ and back to ambient temperature while constrained in the test machine. Further work has been done to investigate the causes for this behavior ${ }^{19}$. That study included X-ray diffraction and differential scanning calorimetric analyses of Nitinol ribbon samples with various thermomechanical histories in an effort to correlate the processing, microstructure and thermomechanical properties.

\section{EXPERIMENTAL ARRANGEMENT}

The SMAHC panel specimen is shown mounted in an aluminum fixture in Figure 9, where it can be seen that only essential fasteners have been installed. The fixture was designed to provide clamped boundary conditions and an unsupported area of $0.356 \times 0.254 \mathrm{~m}$ ( $14 \times 10$ inches). The fixture was also designed to provide electrical connection and mechanical restraint for the Nitinol ribbon leads protruding from the edges of the SMAHC panel specimen. Mechanical constraint for the Nitinol ribbon is accomplished through the use of the gripping assemblies shown mounted to all four edges of the fixture. Detail of the Nitinol gripping assemblies is shown in Figure 10. The carrier of the assemblies is Garolite G10 (a glass-epoxy composite) with knurled, stainless steel inserts fastened in slots machined into the carrier material. Mechanical restraint and electrical connection is made to the actuators by clamping the ribbon between the knurled inserts. The electrical connection is isolated from the aluminum fixture by a thin $(0.0016 \mathrm{~m}, 0.063$ inches $)$ layer of G10 on the inner surface of the assembly, as demonstrated most clearly by the upper two assemblies in Figure 10. It was planned that the substantial tensile load anticipated from the Nitinol actuators would be carried by the in-plane

SPIE's $9^{\text {th }}$ Annual International Symposium on Smart Structures and Materials; Smart Structures and Integrated Systems, L. Porter Davis (Editor), SPIE Vol. 4701, Paper No. 4701-60, San Diego, CA, 17-21 March 2002. 
stiffness of the aluminum fixture by allowing the gripping assemblies to bear on the aluminum fixture edges. Thus, the electrical insulation layer in the gripping assemblies was made as thin as practical to minimize the deformation in the more compliant G10, and thereby minimize the relief (reduction) in the Nitinol recovery load.

The gripping tabs in the top carriers are secured with brass screws to facilitate electrical connection. The electrical jumpers shown in Figure 9 configure all of the Nitinol ribbon in the horizontal direction in series, likewise for all of the ribbon in the vertical direction. Thus, with the installation of a jumper cable shown in Figure 11, the entire array of Nitinol ribbon is rendered electrically in series and a DC power supply connected at the indicated locations allows the entire system to be energized conveniently. Thermal (type-T thermocouples) and vibration (Endevco 2250A-10 accelerometers) measurement instrumentation is also evident in Figure 11. Thermocouples on the aluminum fixture allow indirect monitoring of boundary thermal expansion effects while the panel temperature is controlled by a thermocouple measurement in the lower left corner of the unsupported area, indicated in Figure 9 by an asterisk $(*)$. The thermal controller consists of a process controller (Omega model CN77353-PV) and a DC power supply (HP model $6010 \mathrm{~A})$.

The control thermocouple was located $0.013 \mathrm{~m}$ (0.5 inches) from the left boundary and on the centerline of the lowermost horizontal Nitinol ribbon bundle (over 2 layers of ribbon). This location of the control thermocouple was selected based upon previous experience with SMAHC beam specimens under similar thermal control conditions. Additional control thermocouples, along with a more complicated control metric such as an average temperature, were not incorporated in favor of minimizing the influence on the vibration response and thermal controller complexity. It was anticipated that the selected control thermocouple location would be one of the cooler locations for the Nitinol and that this control configuration would ensure that all of the Nitinol would be at or above the specified setpoint temperature. The significance of this control method is that one can be assured that all of the SMA is fully activated, i.e., above a specified temperature, thereby achieving maximum effect of the Nitinol recovery stress. Thermal analysis of the system was performed to determine the electrical power required to achieve the desired temperature level (fully activate the SMA) and to study the temperature distribution. Results from that analysis indicated that the available DC electrical power $(1200 \mathrm{~W})$ is sufficient and that the resulting temperature distribution would be rather nonuniform. The temperatures in the regions of the crossing points of the horizontal and vertical ribbon bundles (four layers of ribbon) will be greater than that for regions with two layers of SMA because twice the electrical power is being dissipated there. Furthermore, large differences between regions that contain embedded SMA and those that do not should be expected due to the poor thermal conductivity of the glass-epoxy matrix.

The panel specimen and fixture assembly was intended for vibration and noise transmission tests in a transmission loss configuration. A schematic of a transmission loss test facility at NASA LaRC is shown in Figure 12. In this facility, the test article is mounted in a rigid partition between the source and receiver rooms. The excitation considered in this study is normally incident random acoustic pressure with a bandwidth of 50-500 Hz. The acoustic pressure in the plane of the panel was characterized (amplitude and phase uniformity) by an array of five B\&K 4634 microphones prior to installation of the panel-fixture assembly. A microphone at the center of the loudspeaker housing (source microphone) measured the source pressure during this characterization run. The panel-fixture assembly is shown mounted in this facility in Figure 13. The test instrumentation consisted of that previously described for the panel-fixture assembly, the source microphone, an array of six microphones in the receiving room, an infrared camera (FLIR SC2000) in the receiving room, and an air temperature thermocouple in each room. The test procedure consisted of acquiring structural acoustic data at ambient temperature, $65.6^{\circ} \mathrm{C}\left(150^{\circ} \mathrm{F}\right), 93.3^{\circ} \mathrm{C}\left(200^{\circ} \mathrm{F}\right)$, and $121.1^{\circ} \mathrm{C}\left(250^{\circ} \mathrm{F}\right)$. The thermal controller would be allowed to stabilize the panel temperature at each increment before acquiring dynamic data. The thermocouple data would be recorded continuously at 1 sample per minute, while images from the infrared camera would be synchronized with acquisition of the dynamic data. The control thermocouple would be sampled at a much higher rate by the thermal controller and observed during ramp to setpoint, but only recorded at the 1-minute interval.

\section{DISCUSSION}

The SMAHC panel specimen was prepared for structural acoustic testing in a transmission loss configuration as described in the previous section. Upon the first activation of the thermal controller, it was immediately noted that the time constant of the transient thermal response at the control thermocouple was much longer than anticipated and the test

SPIE's $9^{\text {th }}$ Annual International Symposium on Smart Structures and Materials; Smart Structures and Integrated Systems, L. Porter Davis (Editor), SPIE Vol. 4701, Paper No. 4701-60, San Diego, CA, 17-21 March 2002. 
was aborted. Unfortunately, the test was not aborted before the panel was overheated at several locations, one of which precipitated an electrical short between the horizontal and vertical ribbon bundles at the location indicated by an asterisk (*) in Figure 11. The electrical impedance between that location and ground, through the vertical ribbon bundle and including contact resistance, was apparently less than that of the remainder of the intended circuit. Thus, the electrical power was diverted and the relatively high contact resistance of the short caused extremely high temperatures at that location, which caused complete failure of the composite material in that vicinity. Another unfortunate factor is that the infrared camera was not acquiring images during the thermal transient to capture the failure. Immediately following the event, however, images were observed that support the description of the failure. Continuity measurements after this first test confirmed the hypothesis. The test plan was subsequently changed to investigate the causes for the failure and better understand the thermal control performance.

The electrical connectivity at the Nitinol gripping assemblies was altered so as to exclude the leftmost and rightmost vertical ribbon bundles from the circuit. The thermal controller was again activated, but to a much lower setpoint of $35^{\circ} \mathrm{C}\left(95^{\circ} \mathrm{F}\right)$ while also recording images from the infrared camera. A representative image is shown in Figure 14 . It can be seen that several other hot spots exist in the structure. It is believed that these are attributable to "partial" shorts, i.e., connection between coincident horizontal and vertical ribbon bundles over a portion of the potential contact area, that were also precipitated during the first activation of the thermal controller. The nonuniform temperature distribution and large thermal gradient between regions containing four layers of SMA and adjacent regions with no SMA are also noteworthy, both of which were anticipated. The feature that was not anticipated is a large disparity (transient and steady-state) between infrared and surface thermocouple measurements.

For example, the temperature distribution shown in Figure 14 corresponds to a control thermocouple reading of $35^{\circ} \mathrm{C}$ $\left(95^{\circ} \mathrm{F}\right)$. However, the infrared image indicates a temperature of approximately $65.6^{\circ} \mathrm{C}\left(150^{\circ} \mathrm{F}\right)$ in the vicinity of the control thermocouple. This effect is in direct disagreement with similar tests that were performed previously on beam specimens fabricated from the same material system. In the case of the beam specimens, differences between infrared and thermocouple measurements were noted under similar conditions, but were only on the order of about $5.6^{\circ} \mathrm{C}\left(10^{\circ} \mathrm{F}\right)$. Additional tests were performed on the panel specimen to help determine the factors that contribute to the large discrepancy.

The electrical connectivity of the panel specimen was changed to apply power only to the center vertical ribbon bundle. The control thermocouple was moved to the center of the panel. Two additional thermocouples were attached to the panel: one at the crossing of the center vertical bundle with the second horizontal bundle from the bottom, and one at the crossing with the fourth horizontal bundle from the bottom. It is noted that the latter additional thermocouple is of a smaller gauge (24 gauge versus 20 gauge for the type T thermocouples). The thermal controller was again exercised, which resulted in the temperature distribution shown in Figure 15 at a control thermocouple reading of $36.1^{\circ} \mathrm{C}\left(97^{\circ} \mathrm{F}\right)$. In this case, the infrared image indicates a temperature of $32.2^{\circ} \mathrm{C}\left(145^{\circ} \mathrm{F}\right)$ in the vicinity of the control thermocouple (a discrepancy of $\left.26.7^{\circ} \mathrm{C}, 48^{\circ} \mathrm{F}\right)$. Corresponding differences in the vicinity of the other type $\mathrm{T}$ and the type $\mathrm{K}$ thermocouple are $31.1^{\circ} \mathrm{C}\left(56^{\circ} \mathrm{F}\right)$ and $17.2^{\circ} \mathrm{C}\left(31^{\circ} \mathrm{F}\right)$, respectively. This data indicates that the attached thermocouples are generating a large fin effect, extracting and dissipating significant thermal energy from the panel even though the size of the test article is substantial, and are thus measuring a significantly depressed temperature. Figure 15 also shows a nonuniform temperature distribution. This effect is due to shielding produced by the horizontal ribbon bundles because they are located closer to the panel surface than the vertical ribbon bundles. The indication is that the infrared camera is actually measuring an infrared signature consisting of panel surface and Nitinol ribbon components, where that from the Nitinol is attenuated through the translucency of the glass-epoxy composite.

The following remedies are proposed for rectification of the thermal control problem. The specimen should be thermally insulated at the mechanical boundary, if possible, to improve the thermal transient response. Thermal insulation would have the added benefit of reducing boundary expansion significantly, which is a significant source of uncertainty for thermomechanical performance quantification. Thermocouples attached to the panel structure should be of minimum gauge to maintain integrity for the intended environment. The thermal control should be based upon a more comprehensive measurement array such as seeking to achieve a setpoint while assuring other temperatures do not exceed specified limits. Finally, and perhaps most importantly, thermal control should be sought through noncontacting means, such as through temperature data extracted from an infrared camera.

SPIE's $9^{\text {th }}$ Annual International Symposium on Smart Structures and Materials; Smart Structures and Integrated Systems, L. Porter Davis (Editor), SPIE Vol. 4701, Paper No. 4701-60, San Diego, CA, 17-21 March 2002. 


\section{SUMMARY}

A method for fabricating a hybrid composite panel with embedded SMA actuators has been developed. A SMAHC laminate was fabricated from the glass-epoxy matrix with a lamination of (45/0/-45/90/0/90/-45/0/45) and Nitinol ribbon actuators, with a prestrain of $4 \%$, embedded in discrete $0.011 \mathrm{~m}\left(0.45\right.$ inch) strips in four (the two outer $0^{\circ}$ and the $90^{\circ}$ layers) of 9 layers. The overall volume fraction of the Nitinol is approximately $26 \%$. Thermomechanical properties of the constituent materials were presented. Properties presented for the glass-epoxy include elastic moduli and coefficients of thermal expansion. Nitinol properties include recovery stress versus thermal cycle and temperature, at $4 \%$ prestrain, and modulus estimates at various temperatures in the range from ambient to $148.9^{\circ} \mathrm{C}\left(300^{\circ} \mathrm{F}\right)$.

An experimental apparatus was developed to test the SMAHC panel for dynamic response and noise transmission characteristics under the action of thermal and random acoustic loads. The specimen support apparatus consisted of an aluminum clamping fixture for the panel and gripping assemblies for the Nitinol ribbon. The Nitinol gripping assemblies provided electrical connectivity, as well as mechanical support, and were used to configure the entire Nitinol array electrically in series. This configuration was convenient for electrical heating and control. A thermal control system was implemented using a process controller, a DC power supply, the electrical gripping arrangement, and a thermocouple measurement at a strategic location on the panel. The thermocouple placement and control logic were based upon previous experience with beam-type specimens of the same material system and similar configuration. However, upon the first activation of the thermal control system the specimen was overheated at several locations. This failure was attributable to several factors including a much larger thermal time constant than anticipated, a large fin effect produced by the control thermocouple causing it to measure a significantly depressed temperature, and a control strategy that neglected overheat limiting. A scheme for rectification of the problem was identified and included insulating the panel boundary and defining a more complete control metric using thermocouples of minimal gauge or temperatures extracted from infrared measurements.

\section{ACKNOWLEDGEMENTS}

The author gratefully acknowledges the assistance of Cynthia L. Lach, Roberto J. Cano (NASA LaRC), and Stewart Walker (Lockheed Martin) for their help in fabricating the SMAHC panel specimen and processing the Nitinol ribbon. Thanks are also due to Robert A. Baals, Carlton G. Pike, Clyde G. Medley, and Lanier Westbrook (NASA LaRC) for their assistance with the experimental arrangement and data collection.

\section{REFERENCES}

1. V. Birman, "Review of Mechanics of Shape Memory Alloy Structures," Appl. Mech. Rev., 50(11), 629-645, 1997.

2. K. Otsuka and C. M. Wayman (Editors), Shape Memory Materials, Cambridge University Press, Cambridge, UK, 1998.

3. C. A. Rogers and H. H. Robertshaw, "Shape Memory Alloy Reinforced Composites," Engineering Science Preprints 25, Society of Engineering Science, Inc., ESP25.8027, 1988.

4. J. S. N. Paine and C. A. Rogers, "Review of Multi-Functional SMA Hybrid Composite Materials and their Applications," Adaptive Structures and Composite Materials: Analysis and Application, AD-Vol. 45/MD-Vol. 54, 37-45, ASME, 1994.

5. J. Ro and A. Baz, "Nitinol-Reinforced Plates: Part I. Thermal Characteristics," Composites Engineering, 5(1), $61-75,1995$.

6. J. Ro and A. Baz, "Nitinol-Reinforced Plates: Part II. Static and Buckling Characteristics," Composites Engineering, 5(1), 77-90, 1995.

7. J. Ro and A. Baz, "Nitinol-Reinforced Plates: Part III. Dynamic Characteristics," Composites Engineering, 5(1), 91-106, 1995.

8. V. Birman, "Stability of Functionally Graded Shape Memory Alloy Sandwich Panels," Smart Mater. Struct., 6, 278-286, 1997.

9. C. A. Rogers, C. Liang, and C. R. Fuller, "Modeling of Shape Memory Alloy Hybrid Composites for Structural Acoustic Control," J. Acoust. Soc. Am., 89(1), 210-220, 1991. 
10. C. Liang, C. A. Rogers, and C. R. Fuller, "Acoustic Transmission and Radiation Analysis of Adaptive ShapeMemory Alloy Reinforced Laminated Plates," Journal of Sound and Vibration, 145(1), 23-41, 1991.

11. W. S. Anders, C. A. Rogers, and C. R. Fuller, "Vibration and Low Frequency Acoustic Analysis of PiecewiseActivated Composite Panels," Journal of Composite Materials, 26(1), 103-120, 1992.

12. T. L. Turner, "A New Thermoelastic Model for Analysis of Shape Memory Alloy Hybrid Composites," J. of Intell. Matl. Sys. \& Stru., 11(5), 382-394, May 2000.

13. T. L. Turner, "SMA Hybrid Composites for Dynamic Response Abatement Applications," 7th International Conference on Recent Advances in Structural Dynamics, 1, 453-465, ISVR, Univeristy of Southampton, Southampton, UK, 2000.

14. T. L. Turner, "Fabrication and Characterization of SMA Hybrid Composites," Smart Structures and Materials 2001; Active Materials: Behavior and Mechanics, SPIE Vol. 4333, Paper No. 4333-60, Newport Beach, CA, 2001.

15. T. L. Turner, "Experimental Validation of a Thermoelastic Model for SMA Hybrid Composites," Smart Structures and Materials 2001; Modeling, Signal Processing, and Control in Smart Structures, SPIE Vol. 4326, Paper No. 4326-24, Newport Beach, CA, 2001.

16. T. L. Turner, "Thermomechanical Response of Shape Memory Alloy Hybrid Composites," NASA/TM-2001$210656,2001$.

17. D. Goldstein, L. Kabacoff, adn J. Tydings, "Stress Effects on Nitinol Phase Transformations," Journal of Metals, 39(3), 19-26, 1987.

18. K. Sadrnezhaad, F. Mashhadi, and R. Sharhgi, "Heat Treatment of Ni-Ti Alloy for Improvement of Shape Memory Effect," Materials and Manufacturing Processes, 12(1), 107-115, 1997.

19. C. L. Lach, T. L. Turner, K. M. Taminger, and R. N. Shenoy, "Effects of Thermomechanical History on the Tensile Behavior of Nitinol Ribbon," Smart Structures and Materials 2001; Active Materials: Behavior and Mechanics, SPIE Vol. 4699, Paper No. 4699-45, San Diego, CA, 2002.

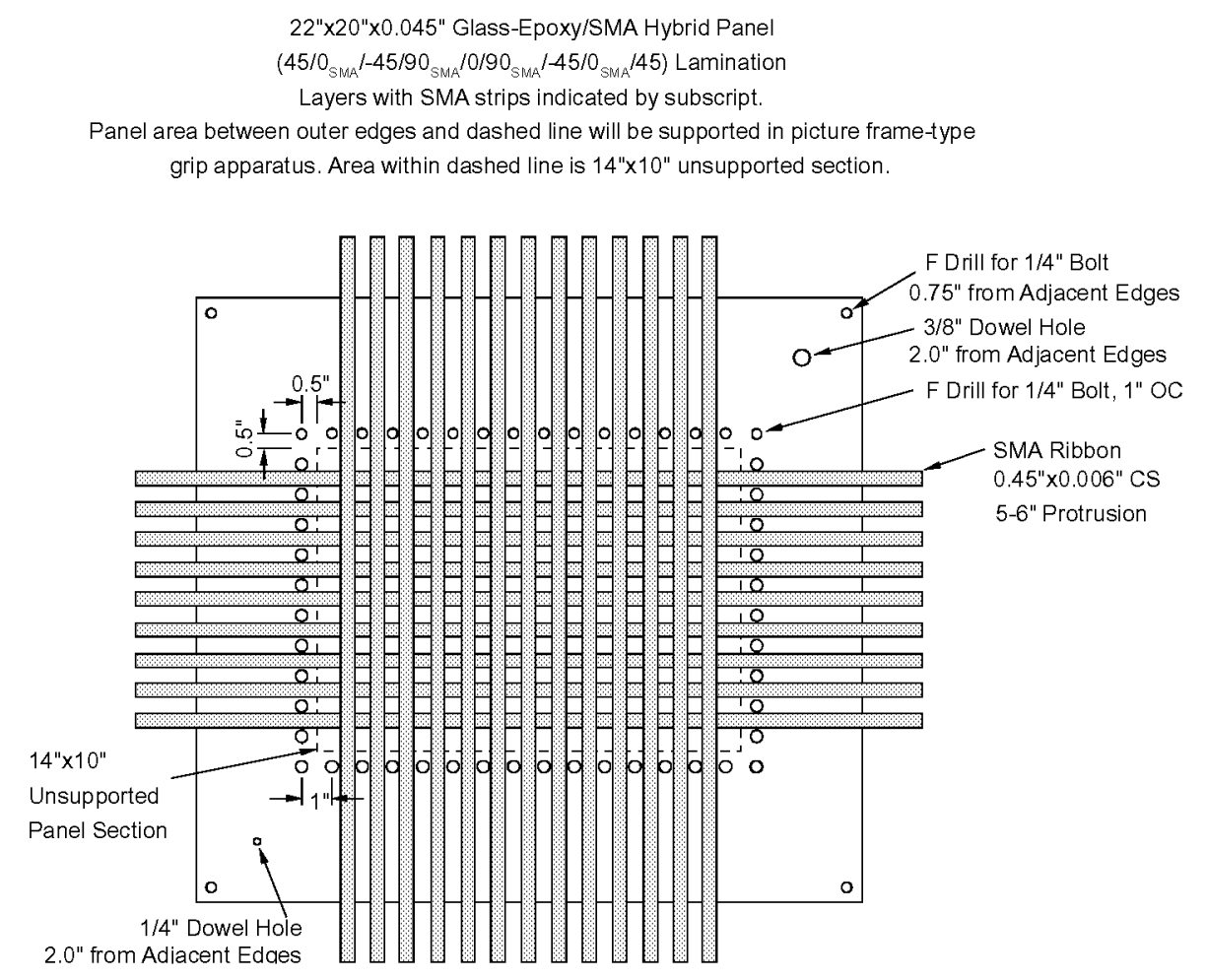

Figure 1: Schematic of the SMAHC panel specimen.

SPIE's $9^{\text {th }}$ Annual International Symposium on Smart Structures and Materials; Smart Structures and Integrated Systems, L. Porter Davis (Editor), SPIE Vol. 4701, Paper No. 4701-60, San Diego, CA, 17-21 March 2002. 


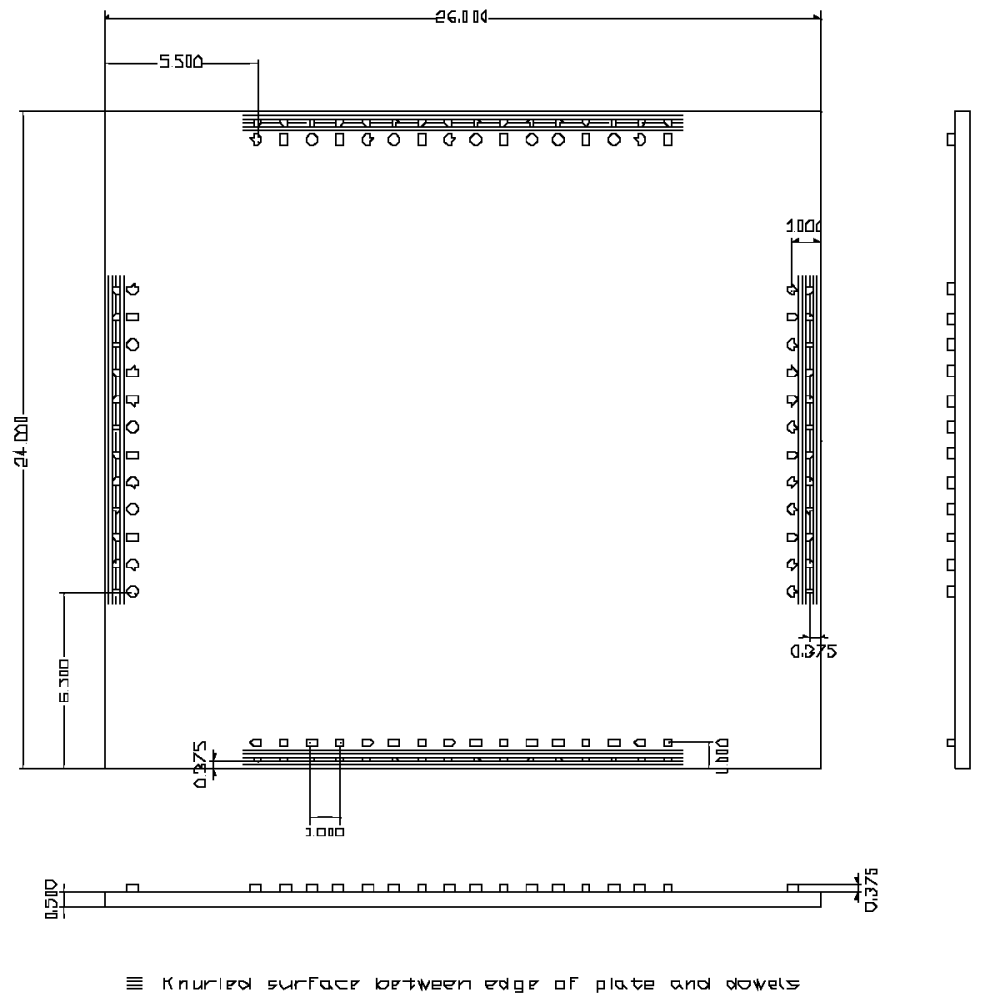

Figure 2: Mechanical drawing of the laminate lay-up and cure tooling apparatus (all dimensions in inches).

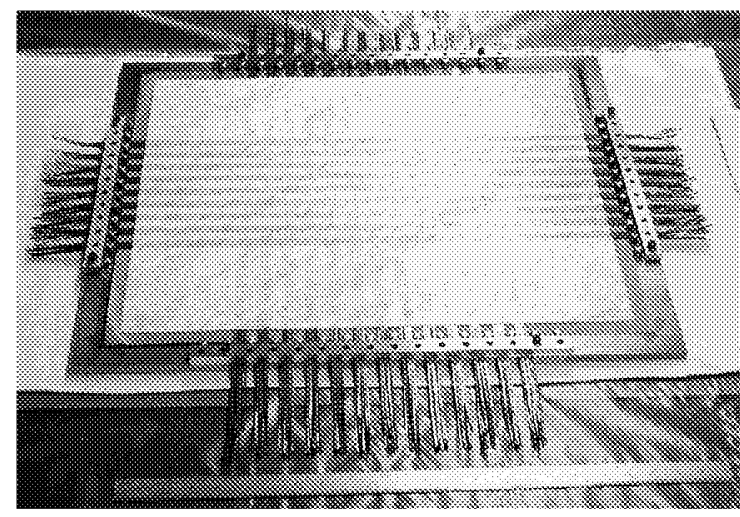

Figure 3: Completed SMAHC laminate with Nitinol ribbon gripped in knurled restraints.

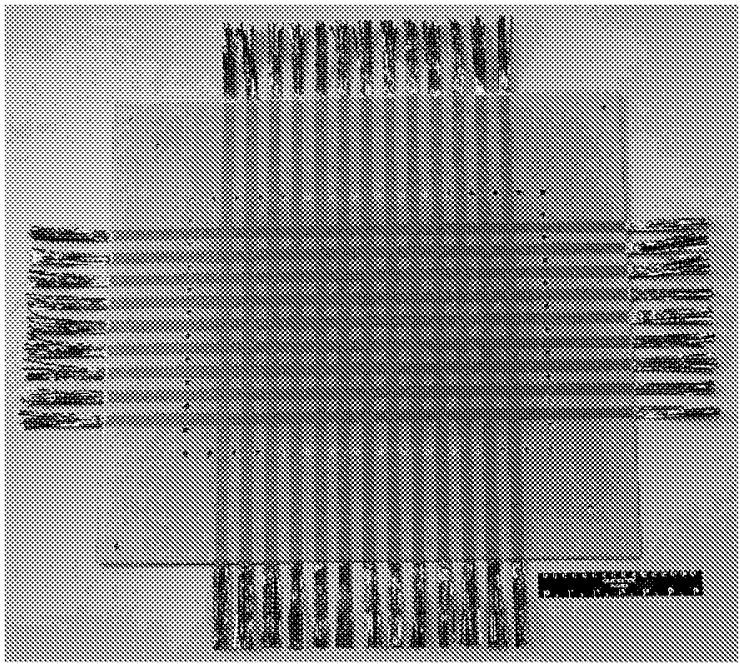

Figure 4: Consolidated SMAHC panel after completion of machine work. 


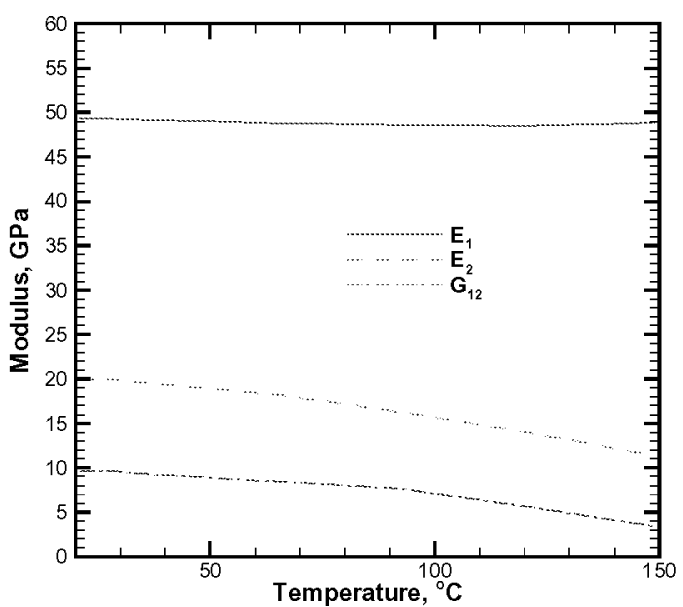

Figure 5: Glass-epoxy elastic moduli versus temperature.

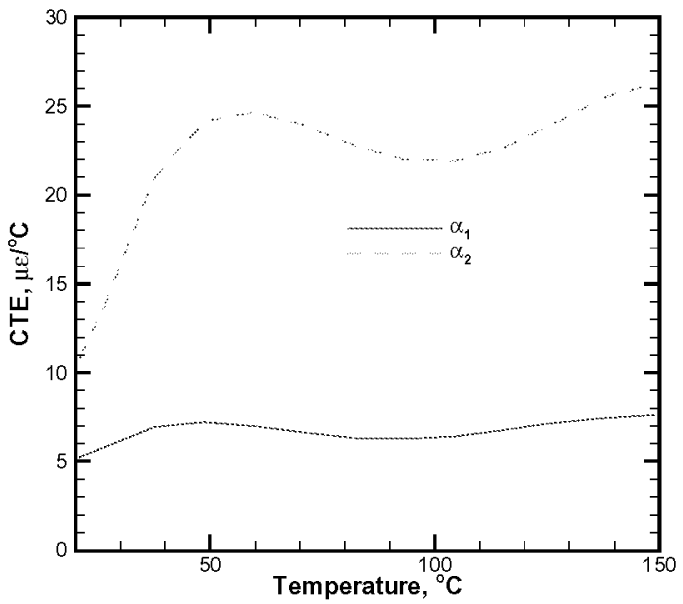

Figure 6: Glass-epoxy CTEs versus temperature.

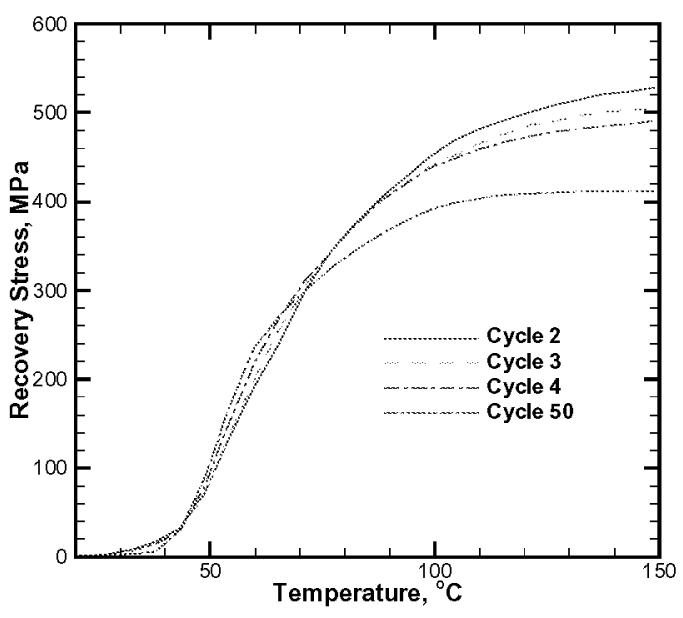

Figure 7: Nitinol average recovery stress versus temperature.

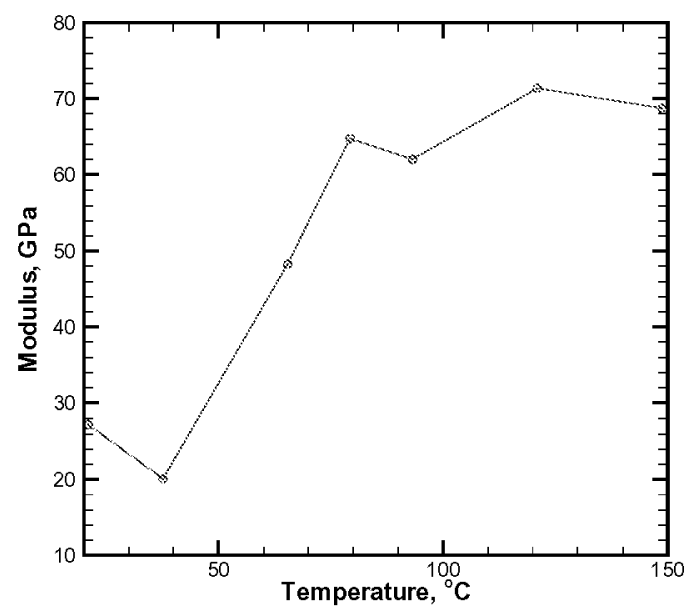

Figure 8: Nitinol elastic modulus versus temperature.

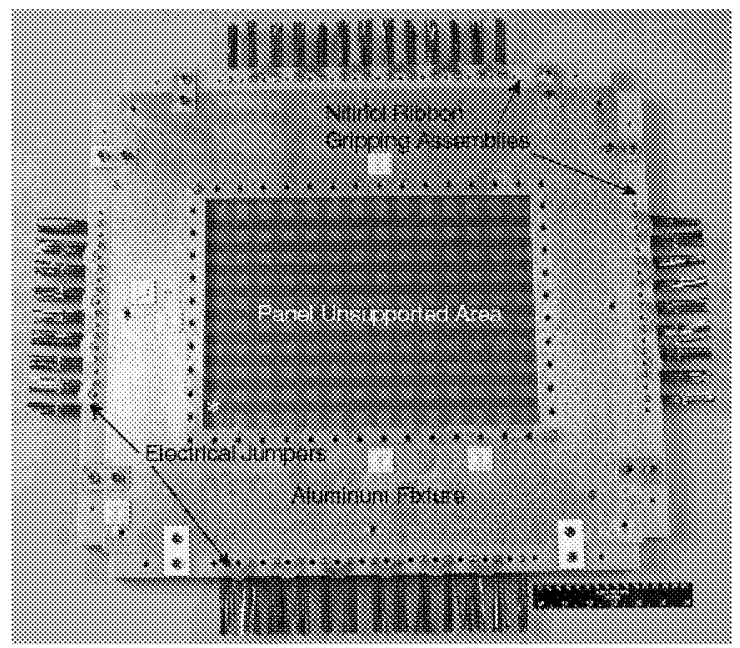

Figure 9: SMAHC panel installed in clamping fixture with Nitinol ribbon gripping assemblies.

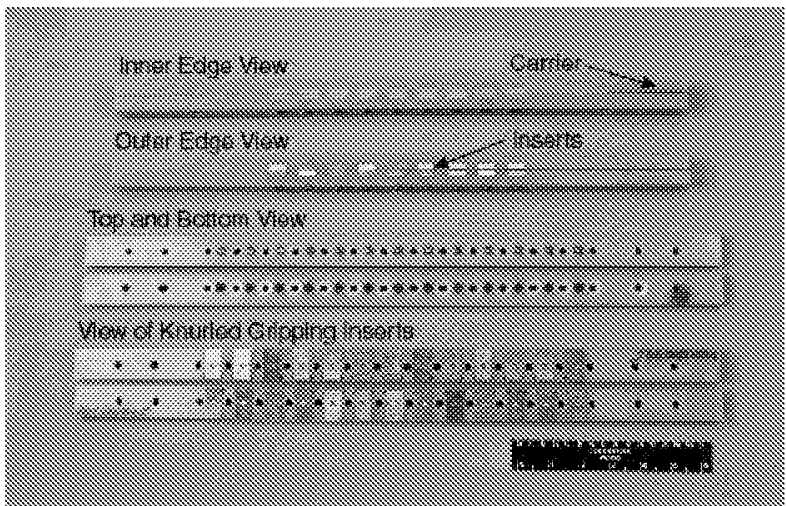

Figure 10: Detail of Nitinol ribbon gripping assemblies.

SPIE's $9^{\text {th }}$ Annual International Symposium on Smart Structures and Materials; Smart Structures and Integrated Systems, L. Porter Davis (Editor), SPIE Vol. 4701, Paper No. 4701-60, San Diego, CA, 17-21 March 2002. 


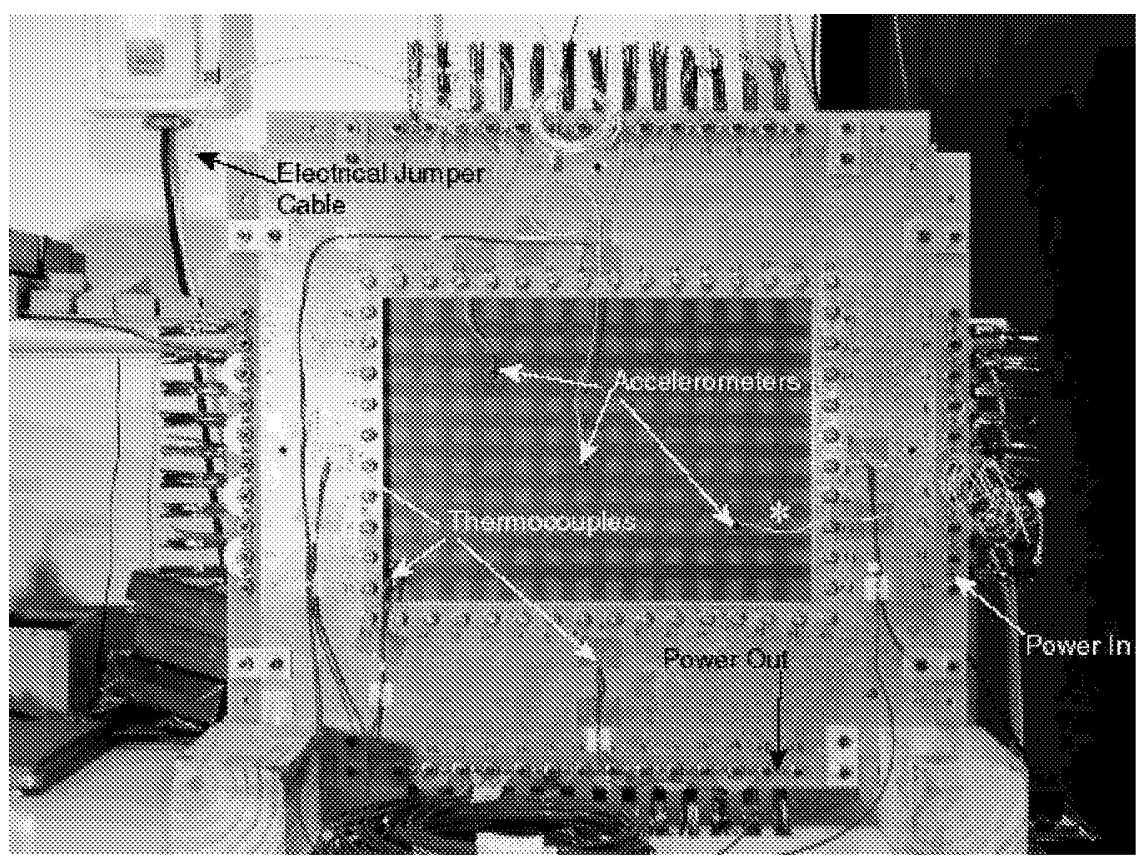

Figure 11: SMAHC panel-fixture assembly with thermal and dynamic instrumentation.

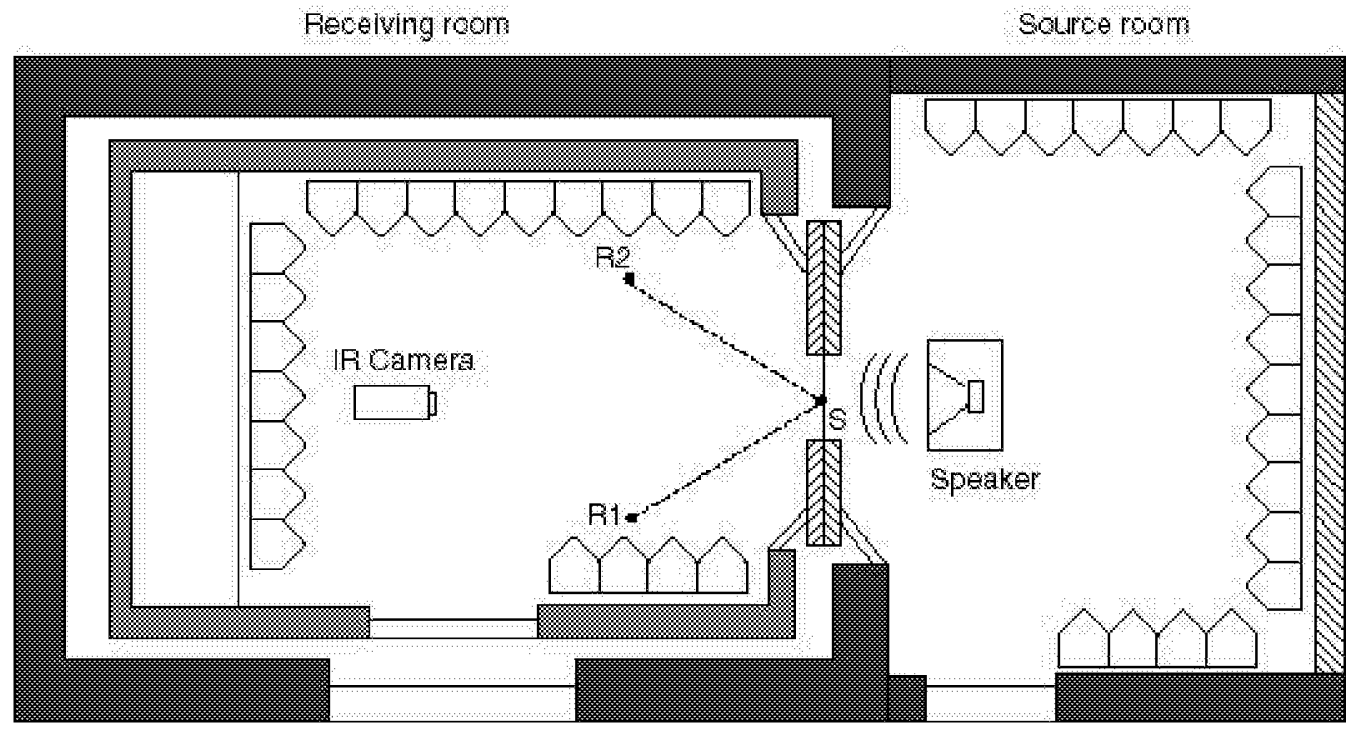

Figure 12: Schematic of NASA LaRC Transmission Loss Facility. 


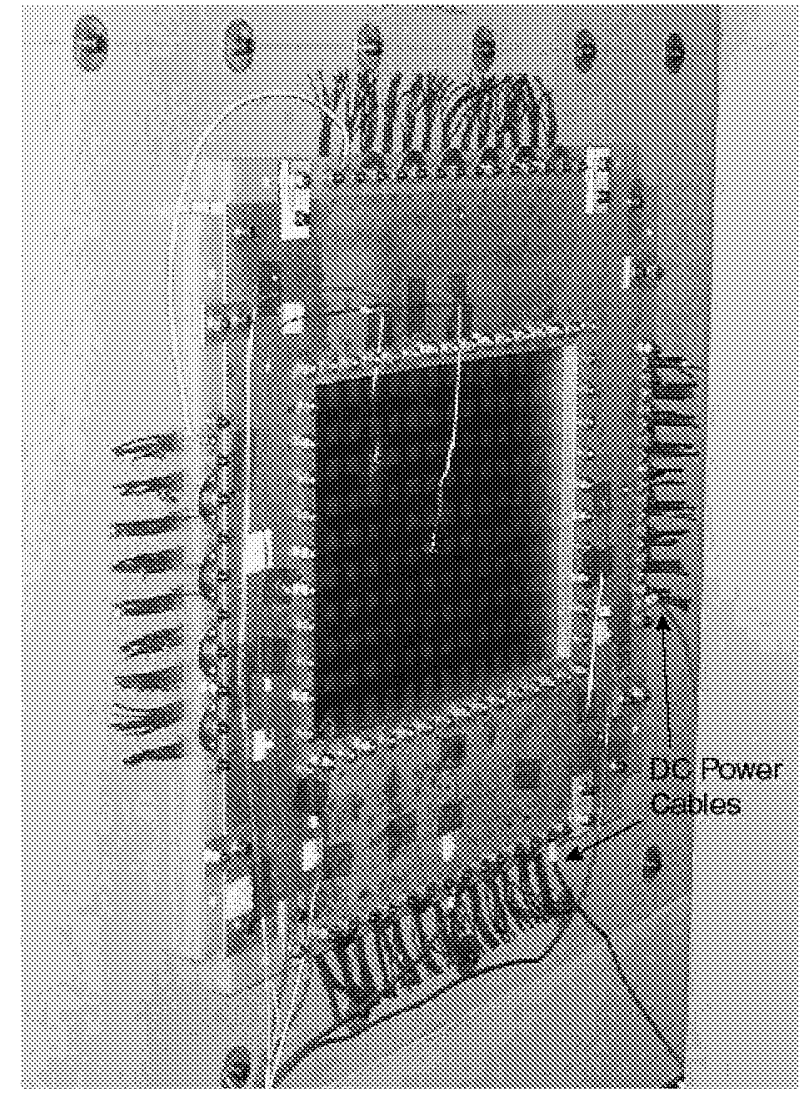

Figure 13: SMAHC panel-fixture assembly installed in transmission loss apparatus baffle.

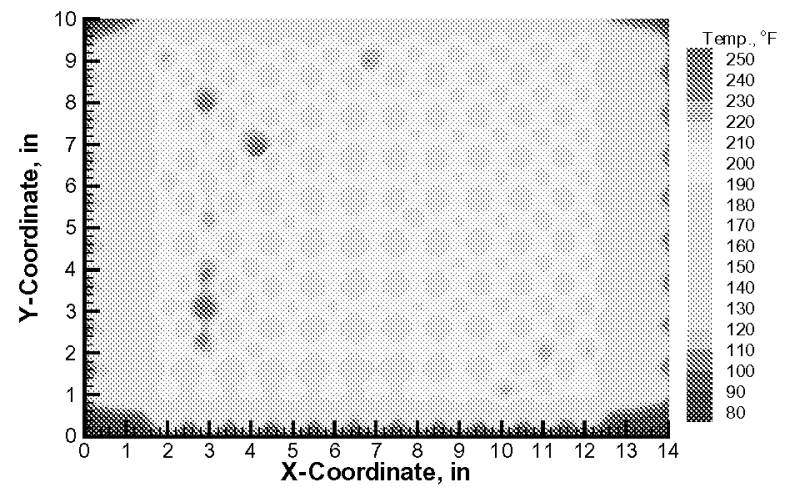

Figure 14: Temperature distribution with 99 of 117 Nitinol ribbon bundles activated at a control TC reading of $35^{\circ} \mathrm{C}$ $\left(95^{\circ} \mathrm{F}\right)$.

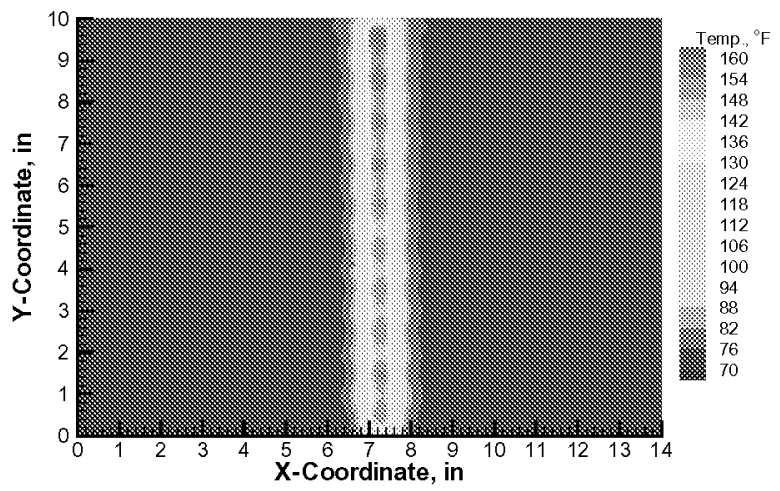

Figure 15: Temperature distribution with 1 of 117 Nitinol ribbon bundles activated at a control TC reading of $36.1^{\circ} \mathrm{C}$ $\left(97^{\circ} \mathrm{F}\right)$. 